\title{
A Study on the Manifestation of Humanistic Thought in Scandinavian Home Design
}

\author{
Yixuan $\mathrm{Lv}^{1, *}$ \\ ${ }^{1}$ School of Art and Design, Wuhan Textile University, Wuhan, Hubei 430073, China \\ *Corresponding author. Email: 2606279733@qq.com
}

\begin{abstract}
Scandinavian design style is a modern design style. Its design began in the late 19th century. It combines modern concise industrial design with traditional decorative elements, pays attention to the actual function of the product, emphasizes the humane concern in the design, and forms a brand new modern aesthetics. During World War I and World War II, Scandinavian countries rose in the field of design and gradually formed a Scandinavian style with extensive influence. Its design has evolved from traditional style to modern style, achieving functional progress and showing the rich simplicity and human touch of traditional handicrafts. This article analyzes the artistic characteristics of the design style by enumerating the materials, decorations, and structures in the home design, and explores the Scandinavian interior home design concept, so as to reveal its unique form of expressing humanistic ideas, expand the field of modern design style, and enrich the cultural connotation of interior design.
\end{abstract}

Keywords: Scandinavian design, humanistic thought, nature, unity

\section{INTRODUCTION}

Home design plays a powerful role in modern society. Scandinavian design style is favored by more people. In order to explore the reasons why the design style is popular, this paper will reveal the unique form of expressing humanistic thoughts in Scandinavian style from the Scandinavian interior design concept, carry on the artistic characteristic analysis mainly through the methods of enumeration, illustration and analogy, and analyze the Scandinavian design concept and purpose, so as to provide new ideas and innovation and broaden the field of interior design in the context of the current design situation in China.

\section{THE MANIFESTATION OF HUMANISTIC CONCEPT IN MODERN HOME DESIGN}

With the prosperity of the world economy, the exchanges between countries have been strengthened. With the economic development, cultural integration is the only way. Especially, the design integration has been greatly improved. The Chinese-style furniture of Ming and Qing Dynasties is gentle and elegant, which has become the new aesthetic pursuit of European countries. While the European court-style design is magnificent, elegant and retro, the exquisite workmanship of its details also affects the interior decoration style of the oriental market. With the continuous improvement of people's living standards, people have unknowingly entered the social tide of modern design commodity economy. People's demand for interior design has also been updated. Instead of paying attention to the existence of its object itself, people pay attention to the beauty, personality, and comfort of home design. Beautifying the home design and the living environment has become the aesthetic needs of people in the new era and the inevitable requirement of improving the quality of life.

In addition to customers, designers' ideas are also increasingly innovative, mostly for the design of products popular with the public. However, from the perspective of design, home design is the product designed for "people". In addition to considering the practicability, designers should combine the preferences of different groups, avoid single, uniform design style, and meet different aesthetic needs.

From the beginning of the founding of the People's Republic of China to the beginning of reform and opening up, the focus of China's design is on practicality and firmness. The later change of concept began at the end of the 20th century, from the pursuit of the original pure and practical to the pursuit of decoration and decoration effects. In 2020, people transform the pursuit of the rich and gorgeous design to the pursuit of truly comfortable and simple design, and the interior design will be people-oriented and comfortable. Especially, the people-oriented design covers the widest range, among which the emerging design ideas are also widely developed. Interior design has changed from the unilateral expression of emotion of the original designer to the participation of both sides, striving for the consistency of effect and inner 
expectation and the unity of functional appearance. The most critical part of the people-oriented concept is to grasp the strength and depth of humanistic spirit in design.

\section{THE MANIFESTATION OF HUMANISTIC THOUGHTS IN SCANDINAVIAN HOME DESIGN}

Scandinavian design originated in five Nordic countries: Norway, Finland, Iceland, Sweden and Denmark. Because they are all located in the highlatitude area near the Arctic Circle, the residents here have maintained the completely traditional handicraft for a long time, and created a refreshing design style, reflecting the quiet, simple and warm design style. When people mention Scandinavia, people will think of blue sky, white clouds, white snow, wooden houses in fairy tales and so on. And these design concepts fully reflect the Nordic people's interpretation of nature and life.

\section{A. Ergonomic design ideas}

People often feel tired and stressed in the hustle and bustle of the city and the fast-paced living environment. At this time, people choose to relax by hiking and integrating with nature. They release their own pressure and absorb natural energy in the nature. People are closely connected with nature, and come from nature. When people are far away from the noise, they have more peace. Therefore, the perfect integration of natural elements in home design make people experience the natural comfort and tranquility after returning home, which is also a major trend of modern design. Scandinavian home design reflects a subtle harmony and support between nature and people, also strengthens the physical comfort and spiritual relaxation of customers, and shows the care of Scandinavian design for people, adapting to human body structure and taking into account human emotions. In addition to the use of natural elements, designers also pay special attention to the fitting degree of household products and human body. For example, the curved surface rubber chair designed by Finnish designer Alvar Alto is very representative of human engineering. On the artistic level, the curved rubber chair has streamline and elegant lines, changeable colors, fresh and lively color matching, bold and innovative materials, and has modern significance. On the practical level, the curved rubber chair is compact, simple and generous in structure, which not only conforms to the modern aesthetics, but also takes care of people's use experience, fits the body shape, increases the comfort of use, and has a strong tendency of functionalism.

At the same time, Scandinavian home design has similar characteristics: changing the stereotyped design style under the large industrial standard production, abandoning the previous serious and cold household geometric form, reflecting a warm humanistic sentiment in innovation, being elegant and comfortable, and never giving up people's practical experience in pursuit of fashion and design. Therefore, Scandinavian design embodies the pursuit of ergonomics research, integrates the design trend, the trend of thrift and environmental protection, and is a design style that contains a variety of thoughts and emotions.

\section{B. Popular design concept}

After two world wars, the most important work of the people of Scandinavia is the post-disaster reconstruction. Therefore, the main task is to design simple and practical products in line with the concept of mass consumption, whether in terms of material or consciousness. The purpose is to expand the market, promote production and consumption. Because of the loss of a lot of resources after the war, the design needs to consider the material resources and needs, so the home design at this time is based on retaining its traditional handicrafts, and the design style is transformed to practicality and modernization. Influenced by the general environment, Scandinavian design is in a more regular and orderly form, showing the beauty, simplicity and warm of nature and emphasizing texture and body feeling. Generally speaking, the design styles of the five northern European countries have strong commonality, namely, respecting the tradition on the premise of ensuring the function, being in awe of nature and ensuring the authenticity of material.

The war has narrowed the whole world scope, and the design styles and schools of various countries will virtually move to a whole form. Scandinavian design gradually went to the world stage during the two world wars in the early 20th century, and attracted a lot of attention. At the same time, it was also affected by the industrial production design. The design based on the traditional handicraft industry turned into simple and modern design serving for the public. In interior design, home design is the best embodiment of its function and modernity. In this period, Scandinavian design development is becoming more and more mature, and has an eternal position on the international stage. World War I and World War II brought many problems, but also brought new challenges and adaptation process to Scandinavia. The design style at this time was different from the modern design method purely for commercial value. It was more pure in the post-war environment, and its cultural background became more and more recognizable. Its design idea became a business card that could represent the people and countries in the region.

\section{Features of humanistic functionalism design}

Scandinavian home design reflects care for people and care for the material itself. Maslow put forward the 
theory of need hierarchy, which divides human needs into five levels: physiological need, security need, social need, respect need and self-realization need. Among them, the first two physiological need and safety need belong to the lower level of human needs, and the latter three needs are at the higher level. The people-oriented style of Scandinavian design meets the low-level material needs and high-level spiritual needs of human beings.

Scandinavian design reflects the concern for both material and emotional aspects, which is hard to be surpassed by other design styles. Kay Bergson, Danish furniture designer, puts forward: "the things we make should be humanized, alive, and warm." Therefore, in order to achieve dual care, all design products also need to express the temperature of home products. The chair should be comfortable to sit on, the table should be practical and free, and the bed should be warm and comfortable. This practical design has won a certain international reputation. This kind of Scandinavian home design with special affinity is called humanism.

\section{THE APPLICATION AND DEVELOPMENT OF ART EXPRESSION IN SCANDINAVIAN HOME DESIGN}

\section{A. Visual art expression in Scandinavian design}

The application of visual art in traditional and even modern design has always occupied the mainstream position, and its forms of expression are also rich and colorful. Visual art, as its name implies, is an art produced by observing people's eyes. Its medium is a design product that shows unique visual effect by combining and matching certain material materials. The ways of expression include painting and sculpture, film and television, architecture, decorative arts and crafts, while the visual art performance in Scandinavian design is to express its simple and natural design language through decorative art and sculpture.

If people want to find the obvious visual art expression, they can refer to Paul Hanningson, the Danish designer. The most famous one of his design works is ph series lamps. This series of lamps are representative works of Scandinavian design that uses artistic visual expression forms. For example, the lampshade design of ph lamps is unique, which is covered by layers or groups of light and thin panels, and each layer of which has a proper radian and light transmittance panel. Compared with glass lampshade, frosted lampshade can give people a softer feeling and disperse the brightness of light source. The highlight of the design lies in the fact that through the lamplight of cascade type, this series of lamps and lanterns can cover the light source on the premise of not affecting the lighting effect of the bulb, so as to avoid the discomfort caused by sudden strong light stimulation to people's eyes. The integrality of lamps and lanterns is strengthened, the whole design works as a whole, and the ray of soft warm color is revealed faintly in white chimney and don't break practical value. This kind of lamp design can be said to break the rigid appearance of the bare tube and straight and hard light frame of studio lighting in the industrial stage. The Scandinavian style lamps have warm feelings. What is more worth mentioning is the bionic design of ph lamps. Its external shape makes people think of soft clouds. With the warm light in the middle, customers can feel the bright moon wrapped by clouds if they enjoy it a little. Therefore, this kind of natural design style with visual art expression is very rich from the appearance alone.

In Scandinavian design, visual art expression not only makes the innovation through appearance, but also pays attention to the impact of color on human vision. Scandinavian Peninsula is an island in the Arctic Circle. It is in the cold winter for a long time. The day time is short and the temperature is cold. Therefore, people's demand for a warm and bright indoor environment is more urgent. When designing furniture products, the designers will use white color as the main color, supplemented by bright color matching. Therefore, there has formed a warm and lively home style, which is very prominent in the furniture design of Aalto and the seat design of Arne Jacobs. All of these not only embody the artistic value, but also have the "flexible" design spirit.

\section{B. Practical application of visual art in Scandinavian design}

After discussing the unique visual expression of Scandinavian design, it is found that its elements are mostly embodied in the form of combining the shape and color of the design objects. The design style emphasizes the beauty of simplicity and elegance in nature, and shows the close relationship between man and nature. People can't help but re-examine the relationship between human beings and nature and the mode of getting along with each other to realize the harmony among "heaven, earth, human and nature". And the appearance of household products imitates the lines and shapes of nature, which is totally different from the resolute and cold modern design style, revealing a strong Nordic style.

Such a design concept also brings people a lot of enlightenments. The way to transfer the design concept to the application is not easy. In today's Chinese home design market, most of the Chinese design prices are more exquisite and expensive, while the rest are simple American design. The design modeling is roughly the same, lacking a certain degree of recognition and atmosphere. In fact, what has been bred in this vast land are not only mountains and rivers, but also unique, implicit, gentle, clear and free cultural atmosphere. 
People can learn from Scandinavian design that seeks design inspiration from local culture and nature, and then form a unique Chinese-style picture in the East. For example, the flower windows, cornices and stone wells in Chinese architecture reveal the ancient delicacy; or the beautiful Danxia landform, karst cave and Yadan landform in China show the beauty; or the small bridges and flowing water, the misty rain in the south of the Yangtze River express the small and exquisite; and there is also the vigorous and heroic spirit in northern frontier. The color, shape and history of all these natural landscapes are worth careful taste and speculation. The carpets in the indoor home design can refer to the unique orange-red pattern of Danxia landform, the shape of vases can refer to the winding undulation of China's coastline, the design of tables and chairs can refer to the Chinese-style window hollowing out to make subtle decoration, and the textile products can borrow the gentleness and delicacy of southern misty rain. While carrying out design innovation, adhering to the principle of respecting nature, considering the quality and cost in the design, improving the experience and care for users, people can also feel the different scenery of mountains and rivers at home. In a room, people can accommodate the world. These are the innovations that designers can create. The designers can soften the elements of modern design by unique traditional design style and integrate them into the national characteristics and spirit. And then, it can become a new unique flower in the field of contemporary design. Design has a long way to go. People must face the impact of design thoughts with a broader vision. It is necessary to stand firm in the design and integrate deeper humanistic concepts. As Mr. Nietzsche said, "the voice of beauty is weak, but he is telling a clear mind."

\section{CONCLUSION}

There is a certain connection between Scandinavian design and Chinese design, that is, there are similarities between them. Their artistic forms tell about the relationship between nature and human beings. Therefore, contemporary design style of China approaches Scandinavian design style more quickly. The China's design of furniture, textiles, utensils and ceramics in Ming Dynasty is world-famous. It can be found that these two design styles have some similarities. For example, in furniture and ceramic works, both of them are simple, fluent, rigid and flexible. To some extent, porcelain in Ming Dynasty also has an impact on Scandinavian ceramics. In today, Scandinavian design occupies a place and is widely used in Chinese people's home decoration. Therefore, the two design styles can be said to influence and penetrate each other in different times and social environments.
The generation and development process of humanistic ideas in design are different in different regions, but the root of their generation is around "people". Under certain social conditions, people begin to evaluate and think about the self-worth. The humanistic thought in Chinese concept is closely related to society, nature and complete climate, and later developed into the field of humanistic customs. Humanistic thought was born in the Renaissance, emphasizing its own value and pursuing its original intention.

When this idea around people collides with Scandinavian design, it makes the original rational and standardized mass production design products have warmth. Scandinavian design is a classic that can stand the test of time. It not only has excellent functions, but also meets the aesthetic needs of human visual form. It also integrates traditional handicraft, traditional culture and regional characteristics into its home design, which makes people feel the courage, natural simplicity and humanistic warmth of a famous family in the room. Scandinavian design is worthy of providing reference experience for the development of Chinese design style, and gives new ideas for China's design trend.

\section{References}

[1] Lin Zhiman. Zhouyi - Ci [M]. Jilin: Jilin Publishing House. 2011. (in Chinese)

[2] Zhu Xiaozang. 300 Song Ci Poems [M]. Jilin: Jilin University Press.2009. (in Chinese)

[3] Wang Shouzhi. History of Modern Design [M]. Beijing: China Youth Press.2002. (in Chinese)

[4] Ren Guojie. Tong Zi Wenyi [M]. Beijing: People's Publishing House, 2013. (in Chinese)

[5] Xia Chengtao. Dictionary of Appreciation of Tang Poetry (new edition) [M]. Shanghai: Shanghai Cihai Press, 1983. (in Chinese)

[6] Pan Yunju. Finding the beauty of art [M]. Changsha: Yuelu Publishing House.2005. (in Chinese)

[7] Yang Fang. Selected works of guo moruo [M]. Wuhan: Changjiang Literature And Art Press. 2007. (in Chinese)

[8] Zhou Pengpeng. I ching [M]. Beijing: Beijing United Press. 2015. (in Chinese)

[9] Xi Chuanji. The history of design art education [M]. Jinan: Shandong Education Press. 2001. (in Chinese)

[10] (Germany) Friedrich Hegel. Aesthetics [M]. Nanjing: Jiangsu People's Publishing House. 2011. (in Chinese) 